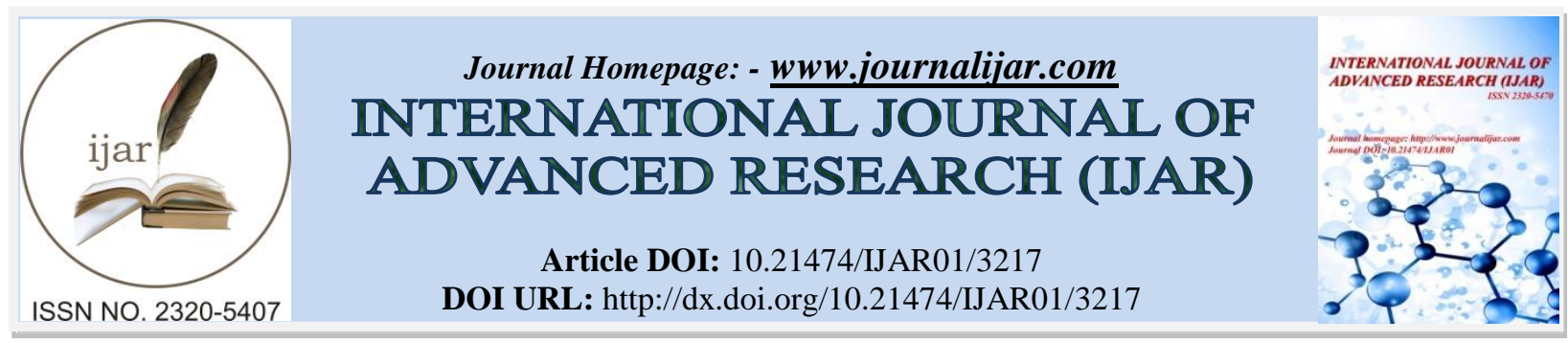

RESEARCH ARTICLE

\title{
IS CONCENTRATION OF FOAM SCLEROTHERAPHY CAN BE DETERMINED PRIOR TO PROCEDURE..?
}

Suraj S. Mahadik.

Department of Surgery, Dr. D.Y. Patil Hospital, Kadamwadi, Kolhapur.

\section{Manuscript Info}

Manuscript History

Received: 19 December 2016

Final Accepted: 15 January 2017

Published: February 2017

Key words:-

Foam sclerotherapy, Varicose vein, STS,

USG.

\section{Abstract}

Objective: Numerous methods of injections and compounds are available. The most commonly used are sodium tetradecyl sulphate, these can be foamed or injected in various concentrations ppresently there is no exact guideline for injection of STS Foam.

Method: we reviewed our prospectively complied data of patient who have undergone USGFS for smaller diameter veins with different concentration of STS and clinical outcome were assed.

Results: There was extremely high patient satisfaction. $81 \%$ registered complete success, and 19\% felt that foam had been partially successful. Their QOL (quality of life) improved as they were more ambulant, could stand for longer duration, could work more, no requirement of compression bandage and felt better.)

Conclusion: Ultrasound guided foam sclerotherapy is a safe, fast and effective technique of treatment of varicose vein. FST seems to more be beneficial for smaller, recurrent, remnant varicosities.

Copy Right, IJAR, 2017,. All rights reserved.

\section{Introduction:-}

The attempts of minimally invasive procedure like sclerosing fluid for the treatment of venous inadequacy have been advancing. At to start with, sclerotherapy was broadly utilized as a trade for surgery, yet it lost enthusiasm after an imminent study, randomized by Hobbs in the 1970. Be that as it may, soon before the start of the 21 st century, another technique created by Tessari restored this topic, supporting the late productions by Cabrera concerning the infusion of polidocanol as ultrasound-guided smaller scale froth known as echosclerosis. ${ }^{(1-3)}$

The likelihood of obliterating the vascular destruction through coagulation was described ${ }^{(4)}$ in the 1950 s. In a different line of exploration, started in France, there was applying cryosurgery for the treatment of varicose veins of the lower limbs. ${ }^{(5)}$ From then on, there was a stamped increment in clinical and exploratory perceptions on the impact of low temperatures on the vascular system. ${ }^{(6-10)}$ Since 1999, the use of endovascular abalation of the saphenous veins with radiofrequency (RF), ${ }^{(11-13)}$ has been concentrated on. Over the previous years, another strategy Endovenous laser photocoagulation indicated promising results for the treatment of varicose veins of the lower limbs. ${ }^{(14,15)}$

Ultrasonography guided foam sclerotheraphy has been in use since last 15 yrs, as modern version developed by cabrea et al. But healthcare are in dilemma to offer this $t / t$ because it is tainted with lack of efficacy and needs special skills, so that in this era other minimally invasive treatment gained popularity like EVLA (endo-venous laser abalation) or radiofrequency abalation. But this minimally invasive treatment option is good for main trunks like 
GSV \& SSV but when it concerned about smaller diameter and superficial vessels the laser treatment became so difficult and sometime it cause skin pigmentation and other complication and definitely needs skills, and literature also says foam sclerotheraphy has adverse effect if injected more than 10cc or if injected in more than 6 to $8 \mathrm{~mm}$ vessels diameter, so considering superficial vessels sclerotherapy is the good minimally invasive treatment.

But there is no exact guideline how much concentration to be used. So we take into account this subject and studied he 44 cases in which primary varices was taken care by endovenous laser abalation and superficial vein was considered for sclerotherapy.

\section{Materials \& Method:-}

All patients came to DYPH hospital with complains of varicose vein, undergoing UGFS for superficial varicose vein, in which truncal varicosities are treated with EVLA between May 2014 to May 2016 were included in study Our study is a non-randomized assessment of foam sclerotheraphy \& its concentration.

All treatment were done as day care surgery using ultrasound machine trucal varicosities were marked and ablated by laser then superficial varicosities marked and its diameter measured and STS foam sclerosant injected. Foam was made by Tessari two-syringe method. ${ }^{(16)}$ It is done with two $5 \mathrm{ml}$ syringeconnected by 3 way cannula. $4 \mathrm{ml}$ air is filled in one and in other diluted sclerosant is taken. Now with repeated alternate pumping and pistoning the two syringes of air and sclerosant foam gets developed. This foam is then injected in to the vein under USG guidance. The movement of foam is assesed on the screen. The Doppler probe is immediately pressed directly over the vein. At least 1 minute time interval was taken for every separate administration of the foam. Patient was asked to dorsi and plantar flex his ankle to clear out any foam which may have entered into the deep vein. When the entire vein segment was seen to be in spasm and foam could be seen occluding the lumen, the needle was removed and compression was applied over the whole limb with leg elevated.

The class II stocking was applied directly along the line of saphenous trunk over padding. Post procedure they were asked to lie supine for 15 min. stocking was left undisturbed with leg elevated for 5-10 days depending upon the size of the vein. Patients were asked to take analgesia (PCM) as per requirement. Patients were asked to walk for 15 min to 1 hour daily.

\section{Statistical analysis}

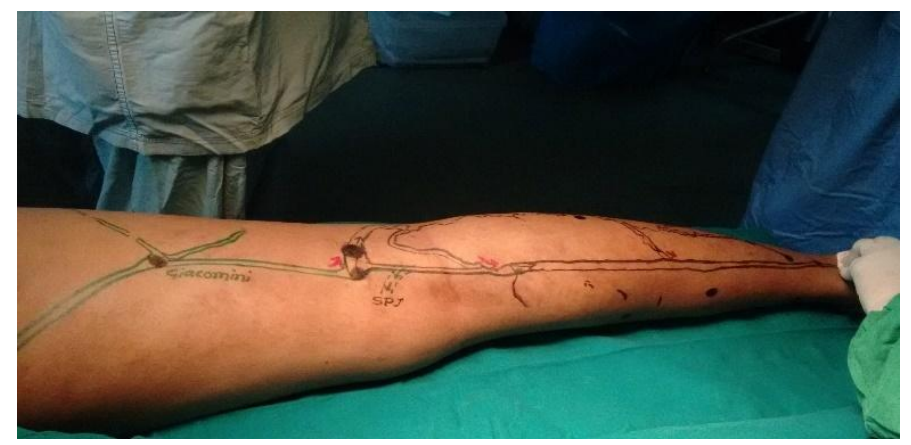

fig no.1 - USG Guided mapping of varicose vein.

During $2 \mathrm{yr}$ of study we have collected data of $44 \mathrm{pt}$ in which we used different concentration of STS. We discharged pt on nxt day of procedure, and followed up at 15, 30, 45 days and metioned their complaints in form of local sign and symptoms like skin pigmentation, phlebitis, pain, cord feeling, induration. We followed our pt at 3 months and at that time follow up colour Doppler was done. Finding noted in terms of sclerosed with minimal local sign and symptoms, moderate symptoms, and partially sclerosed.

\section{Results:-}

Table 1: Concentration of sclerosant (STS) among the study population

\begin{tabular}{|l|l|l|}
\hline Concentration & Frequency & Percentage \\
\hline $\mathbf{0 . 2 5 \%}$ & 23 & $52.27 \%$ \\
\hline $\mathbf{0 . 5 0 \%}$ & 10 & $22.72 \%$ \\
\hline $\mathbf{0 . 1 2 5 \%}$ & 11 & $25.00 \%$ \\
\hline Total & 44 & $100 \%$ \\
\hline
\end{tabular}


Table 2: Diameter of the treated vein among the study population

\begin{tabular}{|l|l|l|}
\hline Diameter of vein & Frequency & $\%$ \\
\hline $\mathbf{1}$ to $\mathbf{2}$ & 11 & $25.00 \%$ \\
\hline $\mathbf{2}$ to3 & 20 & $45.45 \%$ \\
\hline $\mathbf{3}$ to 4 & 7 & $15.90 \%$ \\
\hline $\mathbf{4 t o 5}$ & 5 & $11.36 \%$ \\
\hline$>\mathbf{5}$ & 1 & $02.27 \%$ \\
\hline Total & 44 & $100 \%$ \\
\hline
\end{tabular}

Table 3: Association between diameter of vein and concentration of STS among the study population

\begin{tabular}{|l|l|l|l|l|}
\hline $\begin{array}{l}\text { Diameter of vein/ concentration of } \\
\text { STS }\end{array}$ & $\mathbf{0 . 2 5 \%}$ & $\mathbf{0 . 5 \%}$ & $\mathbf{0 . 1 2 5 \%}$ & Total \\
\hline $\mathbf{1 - 2}$ & 3 & 1 & 7 & 11 \\
\hline $\mathbf{2 - 3}$ & 14 & 3 & 3 & 20 \\
\hline $\mathbf{3 - 4}$ & 4 & 3 & 0 & 7 \\
\hline $\mathbf{4 - 5}$ & 2 & 3 & 0 & 5 \\
\hline$>\mathbf{5}$ & 0 & 0 & 1 & 11 \\
\hline Total & 23 & 10 & 44 & 1 \\
\hline
\end{tabular}

Table 4: Association between Local sign \& symptoms and concentration of STS among the study population at 45

\begin{tabular}{|l|l|l|l|l|l|}
\hline $\begin{array}{l}\text { Concentration/ } \\
\text { complication }\end{array}$ & Pain & Induration & $\begin{array}{l}\text { Cord } \\
\text { feeling }\end{array}$ & Phebitis & Skin pigmentation \\
\hline $\mathbf{0 . 2 5 \%}$ & 2 & 1 & 10 & 0 & 1 \\
\hline $\mathbf{0 . 5 0 \%}$ & 3 & 3 & 8 & 0 & 4 \\
\hline $\mathbf{0 . 1 2 5 \%}$ & 0 & 0 & 2 & 0 & 0 \\
\hline
\end{tabular}

Table no 5: comparison at 15, 30, 45 days

\begin{tabular}{|l|l|l|l|}
\hline Local Signs and symptoms & $\mathbf{1 5}$ days & $\mathbf{3 0}$ days & 45 days \\
\hline Pain & 22 & 13 & 5 \\
\hline Induration & 28 & 20 & 4 \\
\hline Cord feeling & 37 & 32 & 20 \\
\hline Phlebitis & 3 & 0 & 0 \\
\hline Skin pigmentation & 0 & 2 & 5 \\
\hline
\end{tabular}

Table 6: Late follow up on colour Doppler

\begin{tabular}{|l|l|l|}
\hline Follow up & Frequency & Percentage \\
\hline $\begin{array}{l}\text { Sclerosed vein segment with } \\
\text { moderate local signs and } \\
\text { symptoms }\end{array}$ & 11 & $25 \%$ \\
\hline $\begin{array}{l}\text { Sclerosed vein segment with } \\
\text { minimal local signs and symptoms }\end{array}$ & 25 & $56.81 \%$ \\
\hline Partially sclerosed vein segment. & 8 & $18.18 \%$ \\
\hline Total & 44 & $100 \%$ \\
\hline
\end{tabular}


Table 7: association between follow up Doppler and local sign and symptoms at 45 days

\begin{tabular}{|l|l|l|l|}
\hline $\begin{array}{l}\text { Follow up doppler/ local sign } \\
\text { and symptoms }\end{array}$ & $\begin{array}{l}\text { Sclerosed with moderate } \\
\text { signs and symptoms }\end{array}$ & $\begin{array}{l}\text { Sclerosed with minimal } \\
\text { signs and symptoms }\end{array}$ & Partially sclerosis \\
\hline Pain & 3 & 1 & 1 \\
\hline Induration & 3 & 1 & 0 \\
\hline Cord feeling & 7 & 9 & 4 \\
\hline Phebitis & 0 & 0 & 0 \\
\hline Skin pigmentation & 4 & 1 & 0 \\
\hline
\end{tabular}

Table 8: association between concentration and follow up doppler

\begin{tabular}{|l|l|l|l|}
\hline $\begin{array}{l}\text { Local sign and symptoms/ } \\
\text { Follow up doppler }\end{array}$ & $\begin{array}{l}\text { Sclerosed with moderate } \\
\text { signs and symptoms }\end{array}$ & $\begin{array}{l}\text { Sclerosed with minimal } \\
\text { signs and symptoms }\end{array}$ & Partially sclerosis \\
\hline $\mathbf{0 . 2 5 \%}$ & 2 & 15 & 6 \\
\hline $\mathbf{0 . 5 0 \%}$ & 9 & 00 & 1 \\
\hline $\mathbf{0 . 1 2 5 \%}$ & 0 & 10 & 1 \\
\hline
\end{tabular}

\section{Discussion:-}

Sclerotherapy has been frequently used worldwide (alone or in combination with surgery) to treat all types and sizes of varicose veins, primary and/or secondary in nature. ${ }^{(17)}$

\section{Patient Selection:-}

Pre-treatment evaluation includes careful clinical history, physical examination and appropriate diagnostic tests .We in our study did duplex imaging of all patients prior to the intervention. Patient selection is very crucial. Though FST is being used to manage all types of varicosity we excluded large varicosity requiring multiple sessions of FST, for whom we felt surgery will be better option. We had total of 50 patients, 6 were excluded as per exclusion criteria. All diabetic and patients of peripheral vascular disease were also excluded. Our patients age ranged from 12 yr to eldest being $67 \mathrm{yr}$ old. Mean age was found to be $39.29+13.00 \mathrm{yrs}$.

\section{Sclerosing Agent:-}

Schadeck 1995showed that 4\% polidocanol (aethoxysklerol) resulted in more venous spasm following sclerotherapy than 3\% STS although the disappearance of superficial venous reflux following sclerotherapy was not statistically significant. Goldman 2002showed no difference in photographic appearance of varicose veins following sclerotherapy with polidocanol (aethoxysklerol) compared to STS (in varying concentrations, according to vein diameter), although polidocanol caused less skin necrosis .In contrast, Labas 2003showed that STS improved cosmetic appearance of varicose veins and achieved greater symptomatic improvement at six months. For thread veins, 10\% hypertonic dextrose had similar efficacy in terms of sclerosis to 0.15\% STS (Prescott 1992). Complication rates in terms of pain, matting and pigmentation was not significantly different.

We have used STS injection (SETROL), 3\%; $60 \mathrm{mg} / 2 \mathrm{ml}$. No Patient had any known history of allergy to the drug. Patients were counseled about the procedure in detail in language they understood. A patients having heart ailment were also excluded from the study. The medicine was procured from hospital dispensary and similar formulation used in all patients.

\section{Clinical Outcome:-}

As per shown in table no. 1 diameter of veins among study population was maximum between 2 to $3 \mathrm{~mm}$ measured on USG during procedure mean diameter was $2.77+0.94 \&$ we have we used 3 different concentration during study period, firstly to start with study as per author's knowledge we titrated concentration of STS \& used $0.5 \%$ in $! 0$ patients then on follow up we came to know that due to this concentration patient had local signs and symptoms, so subsequently we lowered our concentration and used $0.25 \%$ in 23 patients while $0.125 \%$ in 11 patients and on follow up mentioned patients complaints in terms of pain, 9nduration, cord feeling, skin pigmentation, phlebitis.

We followed our patients at 15,30,45days and after 3 months where we have done follow up Doppler and mentioned status in terms of sclerosed with moderate local signs and symptoms, sclerosed in minimal signs and symptoms, and partially sclerosed. In table no 5 and 6 respectively.

At the end of 45 days as shown in table no 5 we found that only 5 patients had pain as a local complaints snd 20 patient had cord feeling while nil patients had phlebitis,At 3 months follow up as shown in table no 6 maximum of 
25 patients out of 44 had fully sclerosed vein segment with very minimal local signs and symptoms We also compared our data in terms of association between concentration of sclerosant used \& diameter of vein segment in table no 4 , on applying chi square test $\mathrm{p}$ value was 0.005 which shows stastical significance between concentration $\&$ diameter of vein We compared our data in terms of local signs \& symptoms at 15, 30, 45 days in table no 5 which shows $\mathrm{p}$ value of 0.001 .

Association between local signs \& symptoms \& concentration used at 45 days im table no 8 shows p value of 0.04 is not significant but same association at 15 days shows $\mathrm{p}$ value $0 \mathrm{f} 0.7$ which means as post-operative time increases there is decline in local signs and symptoms and improvement of patients QOL.

While association between follow up Doppler \& local signs \& symptoms at 45 days in table no 7 shows 9 patients had moderate signs and symptoms with sclerosed vein segment after using $0.5 \%$ STS foam while only 2 patients has moderate signs \& symptoms and maximum of 15 patients had minimal signs and symptoms with sclerosed vein segment after using $0.25 \%$ concentration, though 6 patient had partially sclerosed vein segment in that patient second setting can be considered because it's always better to avoid localsigns \& symptoms by using higher concentration of foam

We have always used diluted foam given slowly always under USG guidance only. No patient had matting, ulceration, periphlebitis or loss of vision. ${ }^{(18-21)}$ This followed our learning curve. Hamel et al 2003 reported 2 of 80 patients had popliteal DVT after Polidocanol $03 \%$ foam sclerotherapy. Barrett et al 2004 reported 3\% of their cases had minor DVT. They reported Phlebitis which was a sequel of excessive inflammatory reaction of the sclerosing foam had-occurred in 2\% of legs ( 2 different patients ), while Frullini and Cavezzi 2002 and Rabee et al 2004 reported only $1 \%$ of phlebitis. We had three cases of thrombophlebitis which was managed with bed rest, analgesics. No skin necrosis, sclerosant induced ulcer, wound infection or neurasthenia reported in our study because of most likely because of constant USG guidance, and dilute solution of sclerosant.

In our preliminary data, the clinical outcome was full success (no visible varices or incompressibility of the treated vein segment and absent or improved symptoms) in $81 \%$ and partial success was $19 \%$. This study demonstrates a high patient satisfaction with improvement of the quality of life and a high rate of closure of the visible varicosities with foam therapy. Results achieved in this study are comparable with other reports (Brrett et al 2004, Hamel Desnos et al 2003, Rybak 2003, Wright 2003, Frullini and Cavezzi 2002, Frullini et al 2000 and Cabrera et al 2000). Barrett et al 2004 had reported that, 3 months follow up were enough but others (Desnos et al 2003, Rabee et al 2004 and Breu and Guggenbichler 2004) did not accept that because this period was too short to establishment of alternative venous path-way. Hence we followed up our patient for 01 year. We had no patients who were found to have recanalization.

We also compared our data of FST with conventional surgery of SF ligation, stripping of GSV and multiple phlebectomy in terms of recurrence, operation time, hospital admission, antibiotics usage, analgesics, and complications. We had total of 40 patients of open surgery on follow up.

For open surgery along with inpatient admission, usage of antibiotics (3 doses), requirement of analgesic for mean of 48 hours they were admitted for 4- 7 days. 03 of the patients had hematoma and one patient had post op site infection managed conservatively. Operation time for open surgery was mean of 90 minutes. They all required spinal anesthesia. Time for them to return back to normal job was 9- 15 days. On follow up 4 patients had recurrence of varicosity.

Our study was seen in conjunction to other studies in the literature.Lupton et al. 2002 studied patients randomized to receive 2 consecutive treatments (at 1 month interval) with laser irradiation to telangiectasia on one leg and with sclerotherapy on the other leg. The size matched vessels on thighs; knees, calves, ankles and popliteal fossa were treated by the same operator clinical improvement score $26-50 \%$ for both sclerotherapy treated legs and for laser treated legs .At 1 month after $1^{\text {st }}$ sessions and after $2^{\text {nd }}$ session, improvement score of $51-75 \%$ for sclerotherapy treated legs and $26-50 \%$ for laser-treated legs.

\section{Conclusion:-}

Foam sclerotheraphy is good minimal invasive treatment for superficial varicositiesIn our study we done sclerotheraphy in total 44 patient in which the truncal reflux and large tributaries were treat by EVLA.We firstly 
marked superficial varicosity under USG guidance and diameter of affected vein noted.Then according to our experience titer concentration of the foam and injected in marked segment of affected vein under USG guidanceThroughout study we used $0.50 \%, 025 \%, 0.125 \%$ of STS foam sclerosantWe followed our patient at 15 , 30, 45 days and mentioned local signs and symptoms. We correlated our data which shows there is statically significance correlation between concentrations of foam used and diameter of treated vein in view of effectiveness, closure, prevention of known side effectWe also followed our patient at 3 months and color Doppler was done, which shows $57 \%$ of patient gives better results in term of very minimal local sign and symptoms while $25 \%$ gives moderated local sign and symptoms. But all of them went to work within $1^{\text {st }}$ week of treatment. We also correlated our data with follow up Doppler and concentrations used in study which shows no statically significance.So conclusively at the end of study diameter of vein and concentration used has the correlation and as the lower concentration also gives better result and avoid the local sign and symptoms and gives psychological satisfaction to the patient in form of completeness of treatment as visible veins get disappearWe can safely use this $0.25 \%, 0.125 \%$ concentration under $6 \mathrm{~mm}$ of diameter vein. As compared with surgery this procedure is minimally invasive, cost effective, and early return towork

\section{Refrences:-}

1. Cabrera J, Redodo P, Becerra A, et al. Ultrasound-guided injection of polidocanol microfoam in the management of venous leg ulcers. Arch Dermatol. 2004;140:667-73.

2. Coleridge Smith P. Saphenous ablation: sclerosant or sclerofoam? Semin Vasc Surg. 2005;18:19-24.

3. Bergan J, Pascarella L, Mekenas L. Venous disorders: treatment with sclerosant foam. J Cardiovasc Surg (Torino). 2006;47:9-18.

4. Sawyer PN, Pate JW. Bioelectric phenomena as an etiologic factor in intravascular thrombosis. Am J Physiol. 1953;175:103-7.

5. Milleret R, Le Pivert P. Cryosclerosis of the saphenous veins in varicose reflux in the obese and elderly. Phlebologie. 1981;34:601-5.

6. Le Pivert P. Controlled cryosurgery of varices of the lower extremities. A new therapeutic approach. Apropos of 350 cases. Phlebologie. 1987;40:123-48.

7. Cheatle TR, Kayombo B, Perrin M. Cryostripping the long and short saphenous veins. Br J Surg. 1993;80:1283.

8. Garde C. Cryosurgery of varicose veins. J Dermatol Surg Oncol. 1994;20:56-8.

9. Etienne G, Constantin JM, Hevia M. Cryo-stripping: an advance in the treatment of varicose veins. 3811 operated limbs. Presse Med. 1995;24:1017-20.

10. Constatin JM, Etienne G, Hevia M. Technique and results of cryo-stripping in the treatment of varicose veins of the lower limbs. Ann Chir. 1997;51:745-8.

11. Weiss RA, Goldman MP. Controlled RF-mediated endovenous shrinkage and occlusion. In: Goldman MP, Weiss RA, Bergan JJ. Varicose veins \& telangiectasias: diagnosis and management. 2nd ed. Quality Medical Publishing; 1999. p. 217-24.

12. Chandler JG, Pichot O, Sessa C, Schuller-Petrovic S, Kabnick LS, Bergan JJ. Treatment of primary venous insufficiency by endovenous saphenous vein obliteration. Vasc Endovascular Surg. 2000;34:201-14.

13. Goldman MP. Closure of the greater saphenous vein with endoluminal radiofrequencythermal heating of the vein wall in combination with ambulatory phlebectomy: preliminary 6-month follow-up. Dermatol Surg. 2000;26:452-6.

14. Boné C. Tratamiento endoluminal de las varices con láser de diodo. Estudio preliminar. Rev Patol Vasc 1999;5:35-46.

15. Navarro L, Min RJ, Boné C. Endovenous laser: a new minimally invasive method oftreatment for varicose veins - preliminary observations using an $810 \mathrm{~nm}$ diode laser. Dermatol Surg. 2001;27:117-22.

16. Tessari L, cavezzi A, Frullini A. preliminary experience with new sclerosing foam in the treatment of varicose veins, dermatol surg 2001;27:58-60

17. Marting B. Understanding sclerotherapy. Plastic Surgical Nursing 2000;20(4):209-13, 229.

18. Hordegen KM. Treatment of telangiectasias on the lower leg: A new combined method of sclerotherapy and microincisions. Int Angiol 1999;8(2):116-8.

19. Galland RB, Magee TR, Lewis MH. A survey of current attitudes of British and Irish vascular surgeons to venous sclerotherapy. Eur J Vasc Endovasc Surg 1998;16(1):43-6.

20. Lopez L, Dilley RB, Henriquez JA. Cutaneous hyperpigmentation following venous sclerotherapy treated with deferoxamine mesylate. Dermatol Surg 2001;27(9):795-8.

21. American Academy of Dermatology. Spider vein, varicose vein therapy. 